\title{
PELATIHAN TARI LENGGANG PATAH SEMBILAN \\ DALAM KONTEKS PEMENTASAN TARI \\ PADA SISWA-SISWI SMP NEGERI 30 KOTA PALEMBANG
}

\author{
Treny Hera ${ }^{1}$, Rully Rochayati ${ }^{2}$, Naomi Diah B S ${ }^{3}$, Efita Elvandari ${ }^{4}$, Nurdin ${ }^{5}$ \\ Program Studi Pendidikan Sendratasik Universitas PGRI Palembang \\ Email: trenyhera19@gmail.com ${ }^{1}$, rully_iranius@yahoo.com², naomibudisetyaningrum1212@gmail.com³ \\ efitaelvandari@gmail.com ${ }^{4}$, nurdin.cool43@gmail.com ${ }^{5}$
}

\begin{abstract}
Abstrak
Kegitan Pengabdian Kepada Masyarakat adalah salah satu tugas pokok di dalam Tri Dharma Perguruan Tinggi Universitas PGRI Palembang. Capaian kegiatan PKM yang dilakukan adalah siswa mampu menguasai materi sesuai dengan capaian kegiatan. Kegiatn PKM merupakan kegiatan melatih siswa menari tari nusantara yaitu Lenggang Patah Sembilan yang terdapat dalam kompetensi Mata Pelajaran Seni Budaya sebagai cara membentuk karakter siswa dalam menghargai dan mempertahankan nilai suatu karya seni. Salah satu cara mempertahankan keberadaan seni nusantara khususnya seni tari melalui pembelajaran tari penyambutan yaitu tari Lenggang Patah Sembilan melalui pelatihan menari berpasangan pada siswa SMP Negeri 30 Kota Palembang. Kurangnya kompetensi menari yang dimiliki oleh guru seni budaya di SMP Negeri 30 juga menjadi hal yang melatar belakangi kegiatan PKM ini dilakukan. Seiring dengan lestarinya tari nusantara maka perlu juga apreasiasi cara mementaskannya. Melalui pelatihan tari Lenggang Patah Sembilan mampu menciptakan keterampilan siswa dalam mengenali tiga unsur utama tari yaitu wirasa, wirama, dan wiraga.
\end{abstract}

\section{Kata Kunci: Gerak Tari Lenggang Patah Sembilan, Konteks Pementasan Tari.}

\begin{abstract}
The activity of Community Service is one of the main tasks in the Tri Dharma of the University of Palembang PGRI. The achievement of PKM activities is that students are able to master the material in accordance with the achievements of the activity. PKM activities are activities to train students to dance the archipelago dance, namely Lenggang Sembah Nine, which is contained in the competencies of Cultural Arts Subjects as a way to shape students' character in respecting and maintaining the value of a work of art. One way to maintain the existence of archipelago art, especially dance through learning dance reception, is the Lenggang Patah Sembilan dance through paired dancing training for students of Palembang State Middle School 30. The lack of dance competencies possessed by art and culture teachers at SMP Negeri 30 is also the background for this PKM activity. Along with the continuation of archipelago dance, it is also necessary to appreciate how to perform it. Through Lenggang Patah Sembilan dance training, students are able to create skills in recognizing three main elements of dance, namely wirasa, wirama, and wiraga.
\end{abstract}

Keywords: Broken Nine Motion Dance, Context of Dance Performance. 


\section{Pendahuluan}

Pendidikan kesenian khususnya seni pertunjukan nusantara, dipandang sebagai suatu keterampilan dalam mengekspresikan diri pada seni pertunjukan nusantara asli Indonesia yaitu dari rumpun melayu, kepulauan riau. Negara Indonesia memiliki keanekaragaman bentuk seni pertunjukan nusantara yang masing-masing memiliki ciri khas yang menunjukkan identitas daerah masing-masing dimana seni itu lahir dan berkembang.

Keanekaragaman seni tari khususnya tari nusantara sudah selayaknya untuk dikembangkan dan dilestarikan, yang salah satunya melalui pendidikan formal di sekolah.

Pengalaman estetika sebagai tujuan diberikannya pelajaran seni budaya di sekolah dilakukan dengan cara kegiatan apresiasi dan ekspresi/kreasi. Kegiatan apresiasi berkaitan dengan pemahaman materi secara kognitif sedangkan kegiatan ekspresi/kreasi berkaitan dengan kemampuan/keterampilan siswa secara psikomotorik. Apresiasi dan kreasi perlu diberikan kepada siswa-siswi dalam pembelajaran seni budaya di sekolah, karena semakin berkembangnya ilmu pengetahuan dan teknologi, semakin besar pula tantangan dan godaan yang dihadapi siswa dalam upaya mempertahankan keberadaan seni pertunjukan nusantara.

Cara yang bisa dilakukan untuk mempertahankan keberadaan seni nusantara khususnya seni tari melalui pembelajaran tari melayu yaitu tari Lenggang Patah Sembilan melalui pelatihan menari berpasangan pada siswa SMP Negeri 30 Kota Palembang. Kurangnya kompetensi menari yang dimiliki oleh guru seni budaya di SMP Negeri 30 juga menjadi hal yang melatar belakangi kegiatan PKM ini dilakukan. Seiring dengan lestarinya tari nusantara maka perlu juga apreasiasi cara mementaskannya. Melalui pelatihan tari Lenggang Patah Sembilan mampu menciptakan keterampilan siswa dalam mengenali unsur utama tari yaitu wiras, wirama, dan wiraga.

Kegitan PKM tersebut merupakan kegiatan melatih siswa menari tari nusantara yaitu Lenggang Patah Sembilan yang terdapat dalam kompetensi Mata Pelajaran Seni Budaya sebagai cara membentuk karakter siswa dalam menghargai dan mempertahankan nilai suatu karya seni, yaitu seni tari di Kepulauan Riau sebagai rumpun melayu. Akhir dari pelatihan menari tersebut akan dipentaskan dilengkapi dengan musik iringan dan tata rias busana dalam konteks pertunjukan seni.

Berdasarkan UU RI Nomor 20 tentang Sistem Pendidikan Nasional (SISDIKNAS) dan PP RI nomor 10 tahun 1999 bahwa Perguruan Tinggi dapat menyelenggarakan Pengabdian pada Masyarakat sesuai dengan sifat pengetahuan dan tujuan pendidikan tinggi yang bersangkutan.

Pengabdian pada masyarakat adalah kegiatan yang memanfaatkan ilmu pengetahuan dalam upaya memberikan sumbangan bagi kemajuan masyarakat. Seni Budaya sebagai salah satu materi pembelajaran di sekolah memiliki tujuan yaitu memberikan pengalaman estetika kepada siswa dengan harapan menjadi bekal yang berarti bagi siswa dalam menjawab tantangan bagi hidupnya sebagai insan pribadi maupun kelompok masyarakat.

Berdasarkan latar belaknag yang telah dideskripsikan di atas maka Dosen Tari di Program Studi Pendidikan Sendratasik FKIP Universitas PGRI Palembang mengadakan kegiatan pengabdian kepada masyarakat khususnya di lingkungan SMP Negeri 30 
Kota Palembang, yaitu Pelatihan Tari Lenggang Patah Sembilan Dalam Konteks Pementasan Tari. Adapun Tujuan Kegiatan Pengabdian Masyarakat ini adalah:

1) Melaksanakan Tri Dharma Perguruan Tinggi.

2) Melaksanakan Program Kerja Program Studi Pendidikan Sendratasik sesuai dengan capaian program kerja.

3) Memberikan pelatihan dan pengetahuan dalam bentuk penanaman apresiasi terhadap seni tari melayu pada siswa dan guru.

\section{Bahan dan Motode Pelaksanaan}

Bahan pada kegiatan Pengabdian pada Masyarakat ini adalah "Belajar Tari Lenggang Patah Sembilan secara berpasangan dengan unsur pokok tari wirama, wirasa, dan wiraga juga dalam konteks pementasan Tari di SMP Negeri 30 Kota Palembang", Kegiatan ini telah dilaksanakan pada hari Sabtu, 27 Oktober 2018. Pada pukul 08.00 WIB s.d Selesai. Bertempat di SMP Negeri 30 Kota Palembang.

Dalam kegiatan ini diajarkan pelatihan menari Lenggang Patah Sembilan secara berkelompok dengan musik iringan dan mempelajari sebagai tari yang berfungsi sebagai hiburan dalam suatu acara informal dan informal. Hasil daripada pelatihan tari tersebut akan dipentaskan sebagai apresiasi dan bentuk hiburan di SMP Negeri 30 Palembang.

Metode pelaksanaan kegiatan dilaksanakan secara bertahap diawali dengan metode ceramah terhadap materi kontekstual tari Lenggang Lenggang Patah Sembilan dilanjutkan metode demontrsai dan praktik langsung terhadap materi kajian tekstual khususnya opada materi rangkaian gerak tari Lenggang Lenggang Patah Sembilan.
Narasumber pada kegiatan ini adalah dosendosen bidang ilmu seni tari pada Program Studi Pendidikan Sendratasik berjumlah 5 orang, bahan dan pemateri diuraikan pada tabel yaitu:

\begin{tabular}{|c|l|l|}
\hline No & \multicolumn{1}{|c|}{$\begin{array}{c}\text { Nama } \\
\text { Pemateri }\end{array}$} & \multicolumn{1}{c|}{ Materi } \\
\hline 1. & $\begin{array}{l}\text { Efita Elvandari., } \\
\text { M.Sn }\end{array}$ & $\begin{array}{l}\text { 3 unsur pokok di } \\
\text { dalam seni tari }\end{array}$ \\
\hline 2. & $\begin{array}{l}\text { Treny Hera, } \\
\text { S.Pd., M.Sn }\end{array}$ & $\begin{array}{l}\text { Peranan Tari } \\
\text { Lenggang Patah } \\
\text { Sembilan }\end{array}$ \\
\hline 3. & $\begin{array}{l}\text { Rully } \\
\text { Rochayati, } \\
\text { M.Sn }\end{array}$ & $\begin{array}{l}\text { Bentuk Tari } \\
\text { Lenggang Patah } \\
\text { Sembilan }\end{array}$ \\
\hline 4. & $\begin{array}{l}\text { Nurdin, S.Pd., } \\
\text { M.Sn }\end{array}$ & $\begin{array}{l}\text { Fungsi Tari } \\
\text { Lenggang Patah } \\
\text { Sembilan }\end{array}$ \\
\hline 5. & $\begin{array}{l}\text { Naomi Diah } \\
\text { Budi } \\
\text { Setyaningrum, } \\
\text { M.Sn }\end{array}$ & $\begin{array}{l}\text { Deskripsi Gerak } \\
\text { Tari Lenggang } \\
\text { Patah Sembilan }\end{array}$ \\
\hline
\end{tabular}

\section{Hasil dan Pembahasan}

Hasil kegiatan PkM secara garis besar mencakup beberapa komponen sebagai berikut :

1) Tercapaian tujuan pementasan tari Lenggang Patah Sembilan dan bisa diapresiasi oleh SDM Di lingkungan SMP Negeri 30 Palembang,

2) Tercapainya hasil capaian pembelajaran sesuai tujuan kegiatan yang direncanakan yaitu siswa mampu menari dengan wirasa, wirama, dan wiraga.

3) Kemampuan peserta PKM dalam penguasaaan materi bisa dilalui setiap proses pembelajarannya.

Proses kegiatan PKM diawali dengan penyampaian materi berkaitan dengan fungsi tari Lenggang Patah Sembilan, bentuk tari mulai dari gerak sampai dengan penari. Hal ini dimaksudkan agar siswa memahami 
untuk apa tarian ini dipentaskan dan siapa penarinya.

Setelah pemahan secara teori dipahami oleh siswa dengan cara mengulangi materi dan meberikan pertanyaan kepada siswa dan beberapa siswa antusias menjawab pertanyaan, artinya secara lisan teori fungsi tari dan gerak juga penari mampu dipahami oleh peserta PKM.

Pemahan teori kontekstual tari Lenggang Patah Sembilan sudah dikuasai oleh peserta yaitu siswa SMP Negeri 30, maka kegiatan dilanjutkan dengan melatih siswa dan guru seni budaya menari Lenggang Patah Sembilan diawali dengan gerak lenggang di tempat sampai gerak patah sembilan memutar. Cara mengajarkan setiap gerakan diikuti dengan hitungan oleh pemateri.

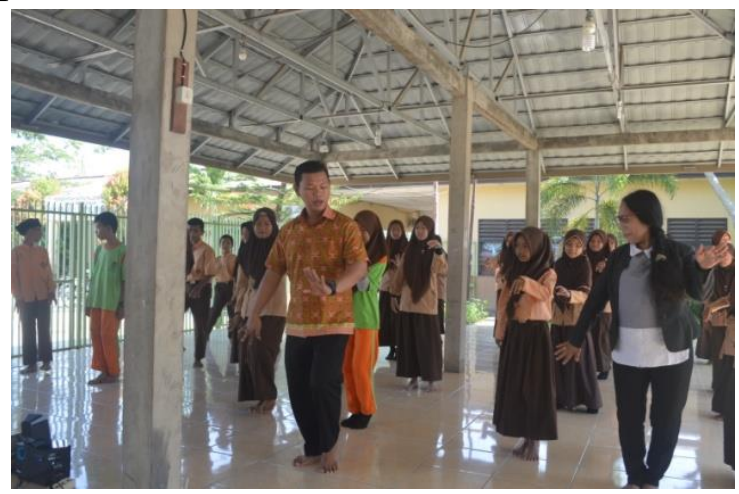

Gambar 1. Pemateri mendemontrasikan gerakan lenggang dengan hitungan dan belum diiringi musik.

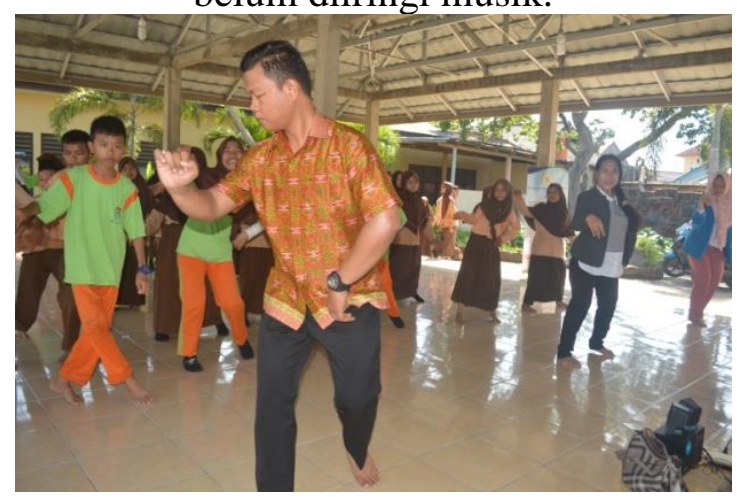

Gambar 2. Pemateri mendemontrasikan gerakan patah sembilan dengan hitungan dan belum diiringi musik.
Latihan gerak dilakukan secara berulang-ulang agar penguasaan menari para peserta PKM dapat tercapai yaitu mementaskan tari Lenggang Lenggang Patah Sembilan beserta unsur pementasannya.

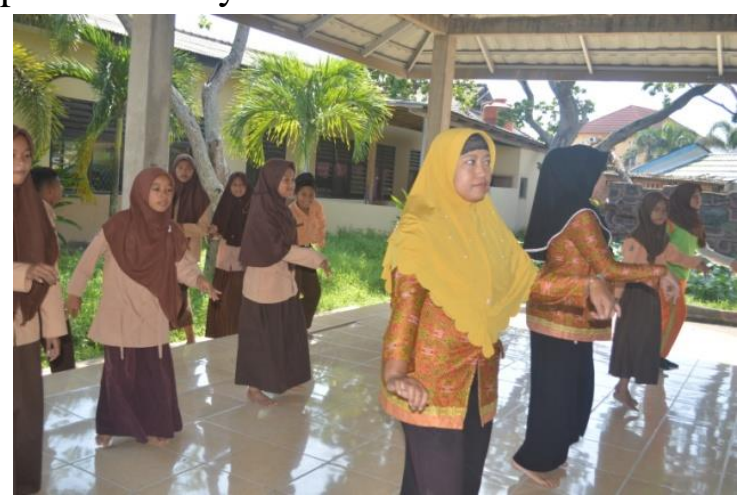

Gambar 3. Beberapa pemateri mendemontrasikan gerakan patah sembilan pada barisan belakang agar seluruh siswa dapat melihat ragam gerakan secara jelas.

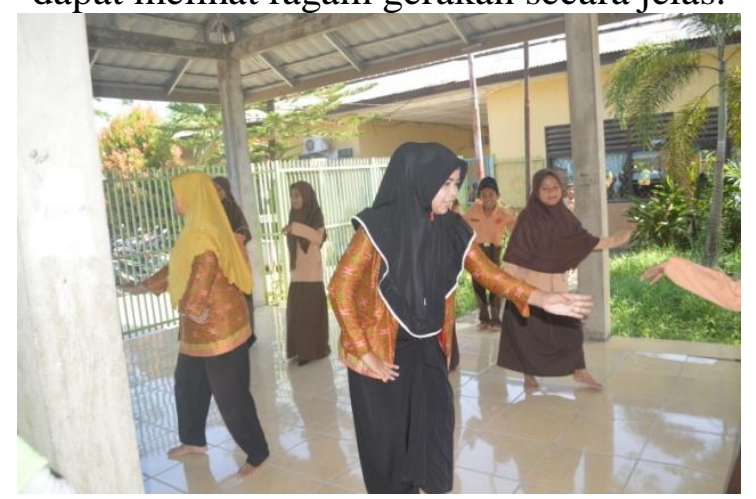

Gambar 4. Pemateri mendemontrasikan gerakan patah sembilan diikuti oleh peserta Pkm

Pemateri mengajarkan gerakan tari Lenggang Patah Sembilan menggunakan metode demonstrasi dan metode drill. Pemilihan metode mengajar tersebut agar seluruh siswa mendapat pengajaran yang aktif juga efesian didalam bergerak. Kesalahan di dalam bergerak yang dilakukan siswa akan dibenarkan oleh pemateri melalui pembelajaran gerak secara hitungan, bertahap, sampai hapalan. 


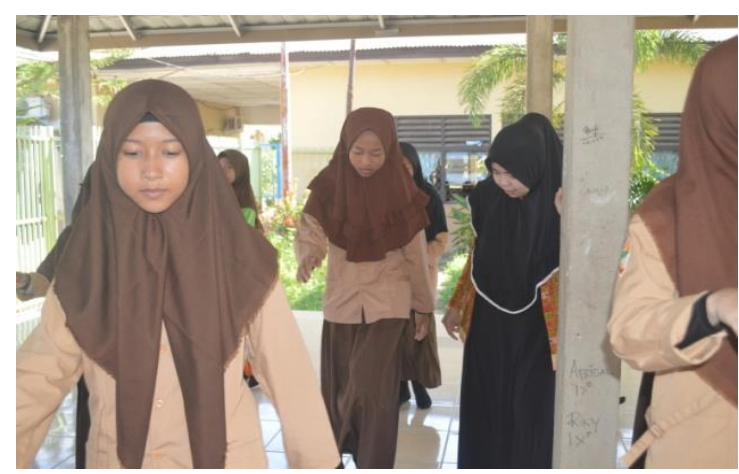

Gambar 5. Pemateri membenarkan gerakan siswa yang salah

Akhir dari belajaran akan diadakan pementasan dimaksudkan untuk memberikan sajian pengetahuan mengenai seni tari nusantara melalui tontonan dan hiburan.

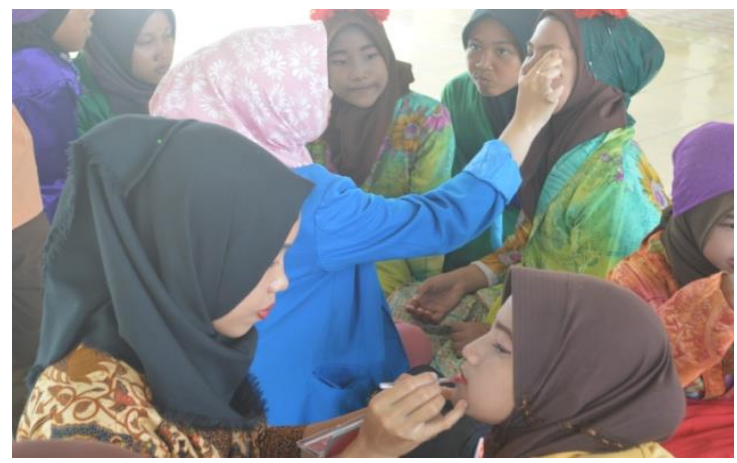

Gambar 6. Persiapan pementasan yaitu merias diri dan menata busana dibantu oleh mahasiswa Prodi Pendidikan Sendratasik.

Tampak siswa senang ketika dihias.

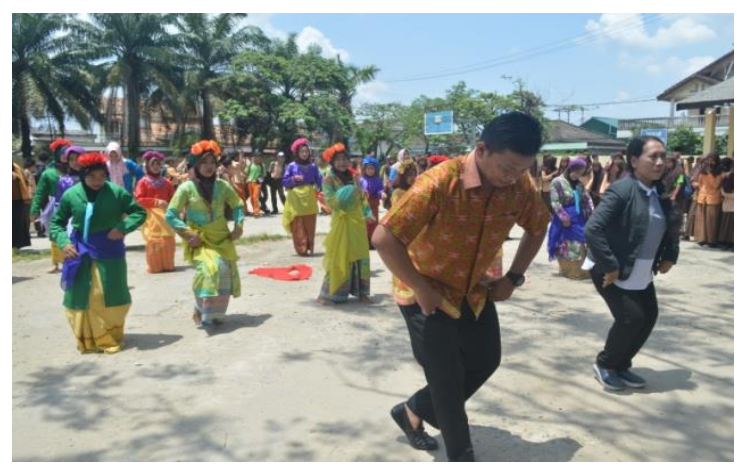

Gambar 7. Hasil dari kegiatan pembelajaran gerak tari Lenggang Patah Sembilan adalah pementasan tari di halaman Smp Negeri 30

ditonton oleh SDM yang ada disekitar sekolah.

Terlihat dari hasil dokumentasi seluruh SDM Di SMP Negeri 30 menikmati pementasan hasil kegiatan PKM dan terhibur dengan adanya siswa-siswi mereka bisa menari dan berpenampilan sebagai seorang penari karena hal ini memang belum pernah dilakukan.

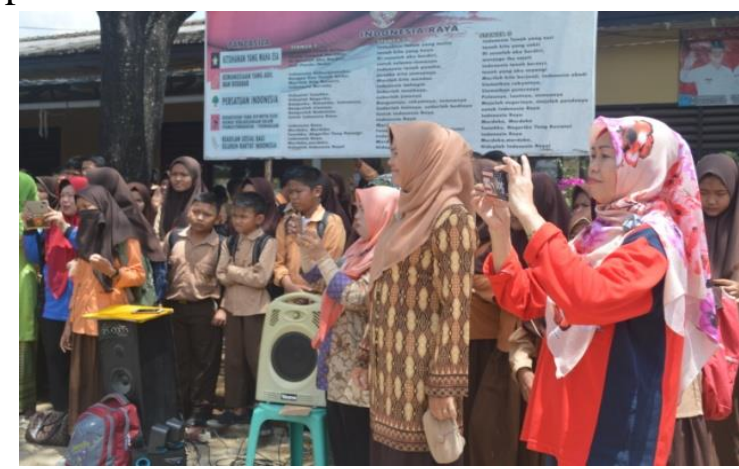

Gambar 8. Antusia guru

mendokumentasikan dan apresiasi yang baik diberikan oleh Kepala Sekolah SMP Negeri 30 melalui menonton siswa siswi pentas tari Lenggang Patah Sembilan.

Hasil dari kegiatan tersebut juga mendapat respon positif dari pihak sekolah, dengan adanya tanggapan meminta kemabali tim PKM agar melakukan kegiatan yang sama dalam waktu dekat.

Ketercapaian tujuan pelatihan Tari Lenggang Lenggang Patah Sembilan secara umum sudah baik, semua materi tentang Tari Lenggang Lenggang Patah Sembilan dapat tersampaikan secara kontekstual dan tekstual sampai dengan persiapan pementasan secara bersama sebagai hasil workshop PKM tersebut.

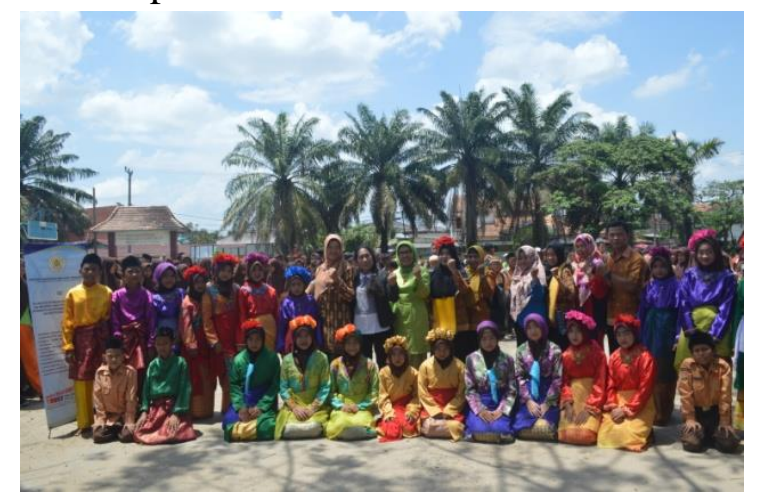

Gambar 9. Foto bersama Peserta PkM dengan Kepala Sekolah SMP Negeri 30 \& 
dewan guru dengan fose melaju dengan mutu.

Dilihat dari hasil latihan para peserta dalam mengekspresikan Tari Lenggang Lenggang Patah Sembilan, maka dapat disimpulkan bahwa tujuan kegiatan ini dapat tercapai.

Tercapainya pementasan tari artinya capaian materi pada kegiatan PkM ini baik, karena semua materi gerak sudah disampaikan secara keseluruhan. Kemampuan peserta dilihat dari penguasaan materi masih kurang dikarenakan kemampuan menari para peserta yang berbeda-beda dan juga motivasi belajar siswa cukup baik, ada juga siswa yang masih malu untuk belajar menari dikarenakan anggapannya bahwa menari itu hanya untuk wanita saja. Akan tetapi secara keseluruhan semua tujuan yang akan dicapai dalam pelaksanaan kegiatan PkM ini sudah tercapai. Namun kegiatan seperti ini akan terus direncanakan dan diagendakan dalam program kerja program studi pendidikan sendratasik.

\section{Simpulan}

Kegiatan pengabdian kepada masyarakat ini berjalan berdasarkan dasar kegiatan dan tujuan yang hendak dicapai, yaitu siswa mampu menari diiringi musik tari dengan unsur pokok tari yaitu wiraga, wirama, dan berwirasa. Salah satu manfaat kegiatan tersebut agar kegiatan PkM memberi kontribusi dalam meningkatkan Tri Dharma Perguruan Tinggi di Universitas PGRI Palembang. Hasil pelatihan menari tari Lenggang Lenggang Patah Sembilan telah diselenggarakan dengan baik dan berjalan lancer sesuai capaian kegiatan.

Hasil pembelajaran gerak tari Lenggang Lenggang Patah Sembilan usai dipentaskan dan telah diapresiasi oleh SDM SMP Negeri
30 dengan cara dipentasakan di depan penonton dilengkapi dengan perlengkapan pementasan seperti pentaan rias, penataan busana, properti tari, dan musik tari. 